\title{
Methodology for quantitative assessment of ecological efficiency of geotechnologies
}

\author{
Yuriy Galchenko ${ }^{1}$ and Julia Ozaryan ${ }^{2 *}$ \\ ${ }^{1}$ Institute of Comprehensive Exploitation of Mineral Resources Russian Academy of Sciences, \\ Russia, 111020, Moscow, Kryukovsky Tup. 4. \\ ${ }^{2}$ Mining Institute FEB RAS, 51 Turgenev st., Khabarovsk, 680000, Russia
}

\begin{abstract}
The article presents the results of work aimed at solving the problem of mining waste generation by creating a methodology of wastefree technology. According to the authors, the problem of solid mining waste can be solved by building a technology with a completely closed cycle of circulation of matter. An integral non-waste coefficient for the field development technology has been proposed, which is defined as the sum of local coefficients obtained for each technological level. By the value of the general coefficient, it is possible to estimate the relative amount of solid waste for an operating mining and processing enterprise, as well as to carry out a comparative analysis of the options considered at the design stage.
\end{abstract}

\section{Introduction}

Scientific and technological development determines the rapid growth in the consumption of natural resources. Even though more than 20 years of research by many scientists and scientific foundations have been aimed at solving the problem of the accumulation of production and consumption waste, issues related to their use and storage are still relevant.

Our contemporary technocratic civilization is almost entirely based on fuel and material extracted from the planet's lithosphere. The geological predetermination of mineral deposits cements mining enterprises as the ruinous vanguard of anthropogenic invasion of ecosystems, and their subsequent annihilation. That is why, taking into account the outstripping growth of the mineral resource complex and the scale of the destructive consequences of its development, the degree of environmental hazard of the applied methods of subsoil development determines practically the entire prospect and form of the existence of natural biotopes in vast territories. A fundamental place in the overall development is occupied by the mining, metallurgical and energy complexes, for the development of which a person annually extracts huge volumes of ore, fossil fuels and building materials from the bowels of the Earth. The industry of mining solid minerals plays a leading role in the formation and accumulation of solid waste on the planet's surface, the amount of which is at least $65-70 \%$ of the total extracted of lithosphere matter [1].

Extraction of minerals leads to strong hydrobiogeochemical changes in the ecosystem [2] and is considered one of the most destructive types of economic activities for its contribution to the deterioration of the function of ecosystems and, an increase in surface which

* Corresponding author: ozaryanigd@gmail.com 
contributes to: the emergence of flooding zones [3-8], climate change, loss of habitat [9] and changing landscape demographics [10-12]. So in the process of developing coal deposits by the open method, the transfer of dust flows affects the state of soils and vegetation in the affected area.

Monitoring systems, which utilize modern GIS technologies, are vital in the study of the ramifications of mining on the biosphere and environment as a whole [13, 14].

By monitoring and mapping soil degradation, it is possible to determine an effective reclamation scheme, thereby reducing and preventing an increase in the risk of soil degradation [15].

For example, numerous articles contain recommendations on methods for improving the state of land for modern open pit mines and increasing their fertility [16-22], discuss the development of a reclamation strategy, the possibilities of using it for plant growth and soil development, and taking into account environmental problems.

Russian researchers [23, 24] believe that in a dry continental climate, especially with strong winds, conditions are created for the intensification of the entry into the surface layers of the atmosphere and the movement of dust and gas pollutants in them.

At the same time, it is quite obvious that even the most reliable monitoring of the environmental consequences of the accumulation of mining and processing waste in the ecosystems of the natural biota of the Earth cannot provide a solution to the problem under consideration. All possible solutions are associated exclusively with the creation and application of geotechnologies with a closed cycle of circulation of the extracted lithosphere matter. At the same time, it is no less obvious that it becomes necessary to create methods for quantitatively assessing the level of environmental efficiency of the technologies used, allowing them to be compared and selected at the stage of making technical decisions.

\section{Results and discussion}

In its most general form, the problem of solid mining waste can be solved by building a technology with a completely closed cycle of circulation of matter.

In the system of subsoil development, the initial lithosphere material turns into the final product of economic use, passing through several levels of its change (technological levels).

Through of prospecting in the volume of the lithosphere, the position of areas with abnormal, in relation to clarke, contents of certain useful components is determined. At the stage of general searches, the allocation, delineation and geological and economic assessment of the predicted resources in the $\mathrm{R}_{3}$ category are carried out.

As a result of further exploration of promising territories, forecast resources of the R1 category are determined.

At the same time, the number of predicted resources of the $\mathrm{R}_{2}$ category, as a result of the refinement of the primary information, slightly decreases in relation to the $\mathrm{R}_{2}$ category. With the further development of these works, resources of the $\mathrm{R}_{1}$ category are determined.

At each stage, the size of the potential lithosphere area decreases by a certain amount, which can be considered waste that remains in place of its occurrence.

Within the established contours of predicted resources of category $\mathrm{R}_{1}$, a complex of exploration work is carried out, the task of which is to identify deposits and find out their industrial significance. In terms of the content of useful components, explored reserves are subdivided into on-balance sheet and off-balance sheet. Balance reserves, in order to increase the reliability of information about their quality, in turn, are divided into categories $\mathrm{C}_{2}+\mathrm{C}_{1}$ $+\mathrm{B}+\mathrm{A}$. At the same time, the amount of reserves in each subsequent category, as the quality increases and the reliability of exploration increases, decreases. This amount can also be considered as solid waste of this process remaining in the lithosphere. 
The specificity of the subsoil development process lies in the fact that between the technological levels of exploration and development of the field there is an intermediate level at which, as a result of a complex of design work, the field is identified as an object of development. At this technological level, as a result of substantiation and selection of geotechnological solutions, as well as an assessment of their capabilities to ensure the completeness of extraction, geological reserves are transformed into commercial and operational reserves. Here, the volume of structural losses of a mineral can be considered as conditional waste when performing the stage of technological transformation of the lithosphere substance.

At the next technological level, as a result of mining operations, mined rock mass is produced, consisting of disintegrated lithosphere material and including ore and rock mass. The ore mass enters the next level - primary processing, and the rock mass is released to the surface and accumulates in dumps. At the stage of primary processing, the ore mass is separated into concentrate, which goes for further use in another technological system, and into waste (tailings) of concentration, which, like waste rock, remain at the processing site in the form of storage facilities of various designs. That is, at each technological level, the incoming lithosphere material is divided into two parts. One part, carrying the main amount of the useful component, goes to a higher level, while the other remains at the same level (Fig. 1).

Just like in a biological system, the substance passing to a higher level decreases in mass, and the remaining substance accumulates from level to level and forms an increasing volume of waste. The only difference is that the "biological pyramid" of the movement of matter functions due to the energy of the Sun, and the "technological" one - due to the labor of Man. Otherwise, the qualitative identity of the processes is quite obvious. This makes it possible to use one of the fundamental provisions of homeostatics on how to maintain the parameters of interacting systems by managing contradictions.

The biotic and abiotic parts of the ecosystem are linked into a single system by the continuous exchange of material (circulation of nutrients), for which the Sun supplies energy. During the development of the mineral resources of the Earth's bowels, the lithospheric and technospheric parts are also linked into a single system of subsoil development by the continuous exchange of lithosphere matter in the form of a circulation of economically significant components and waste in the anthropogenic technological system. With regard to the problem of the formation of environmental hazard during the storage of solid waste, this indicates a complete similarity in the nature of the movement of biological and lithospheric matter in natural ecosystems and in the systems of subsoil development, which makes it possible to use indicators identical to the indicators of the overall ecological efficiency of biological systems $\left(\mathrm{F}_{\text {эк }}\right)$ :

$$
F_{\ni \kappa}=\sum_{i=1}^{i=n} \frac{B_{r i}}{B_{b i}}
$$

where $\mathrm{B}_{\mathrm{ri}}$ is the net transition to the next level, produced biomass; $\mathrm{B}_{\mathrm{bi}}$ is the gross (primary) biomass produced at a given trophic level.

By analogy with the current indicator of the ecological efficiency for each trophic level of the biological system, the efficiency of using the lithosphere matter at different stages of its movement in the technical system of subsoil development can be estimated by the value of the local (or current) coefficient of the efficiency of using the lithosphere matter (KB), which is the ratio of the amount of matter, which was used to obtain a product moving to the next technological level $\left(\mathrm{Q}_{i}+1\right)$. Since at any technological level the following ratio is observed: $\mathrm{Q}_{\mathrm{i}}+1=\mathrm{Q}_{\mathrm{i}}-\mathrm{Q}_{\mathrm{ot}}$ (where: $\mathrm{Q}_{\mathrm{ot}}$ is the amount of waste generated at a given technological level), the above KB indicator also characterizes the degree of wastelessness of processes, transformation of lithosphere matter at a given technological level. 
In accordance with the schematic diagram shown in Fig. 1, the main task of the prospecting stage is the detection and preliminary assessment of potential anomalies in the concentration of useful components by performing a set of works that ensure the transformation of the metallogenic potential of the territory into predicted resources of category $R_{3}$ and the transfer of these resources to higher categories of $R_{2}$ and $R_{1}$.

An indicator of the effectiveness of the prospecting stage is the delineation of promising exploration areas and the assessment of their resources according to the $\mathrm{R}_{1}$ category, which are to be sold into reserves during further exploration. Therefore, prospecting work should be considered as the first stage in the involvement of lithosphere matter into economic circulation as the beginning of the process of integrated development of the subsoil.

The local (current) coefficient of no waste at this level of development $\left(\mathrm{K}_{\mathrm{B} 1}\right)$ is defined as the ratio of the volume of predicted resources of the highest category $R_{1}$ to the volume of resources of the category $R_{3}$.

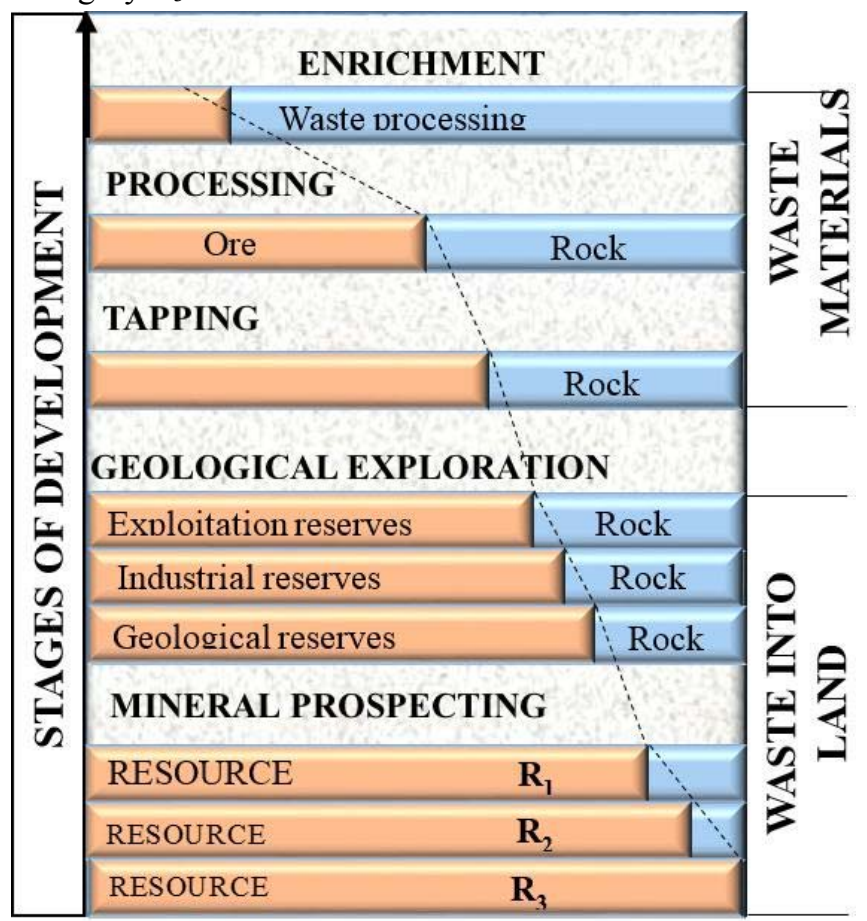

Fig. 1. Diagram of the movement of lithosphere matter in the process of subsoil development

- the substance of the lithosphere involved in economic circulation

-lithospheric material remaining in waste

$$
K_{B 2}=\frac{\sum R_{\text {geol }}}{R_{1}}
$$

In general, exploration work provides a geological basis for the subsequent design of the field development as the next technological level. At this level, as a result of justification, selection and consideration of the features of the application of technological solutions, the operational reserves of the field are determined, the value of which is $\left(\sum \mathrm{R}_{\text {екс }}\right)$ is a product that moves to the next technological level: 


$$
\sum R_{e \kappa \mathrm{c}}=\left(\sum R_{b a l}-P_{\mathrm{K}}\right) \cdot\left(1-\mathrm{K}_{\mathrm{cK}}\right)
$$

where $P_{k}$ - structural losses for the considered development conditions; $K_{c k}$ is the coefficient of quality reduction due to the dilution of a mineral when using design technological solutions. Since an obligatory element of the design of any mining enterprise for open-pit or underground development of a deposit is the solution of the issue of its opening, the composition of the initial volume of lithospheric material must, in addition to operational reserves, include the total volume of these works performed on the enclosing rocks $\left(\mathrm{W}_{\mathrm{BC}}\right)$. Then the technology waste-free factor $\left(\mathrm{K}_{\mathrm{bz}}\right)$ at this level will be:

$$
K_{b z}=\frac{\sum R_{e \mathrm{KC}}+W_{\mathrm{BC}}}{\sum R_{\text {geol }}}=\frac{\left(\sum R_{b a l}-P_{\mathrm{K}}\right) \cdot\left(1-\mathrm{K}_{\mathrm{cK}}\right)+W_{\mathrm{BC}}}{\sum R_{\text {geol }}}
$$

If the project provides for the extraction of off-balance reserves with their subsequent storage on the surface, then the value of the coefficient is determined by the formula:

$$
\mathrm{K}_{B 3}^{\prime}=\frac{\left(\sum R_{\text {геол }}-P_{\mathrm{K}}\right) \cdot\left(1-\mathrm{K}_{\mathrm{cK}}\right)+W_{\mathrm{BC}}}{\sum R_{\text {геол }}}
$$

Since any mining enterprise has a limited lifetime, and its main characteristic is annual ore production, then to determine the coefficient of efficiency of the use of lithosphere matter at the stage of deposit development and subsequent stages, it becomes necessary to take into account the time factor by changing the dimension of all volumetric indicators and using them in the annual expression.

At the technological level, the field development will be:

$$
K_{B 4}=\frac{W_{\mathrm{pM}}+W_{\mathrm{BC}}}{\sum R_{e \mathrm{KC}}+W_{\mathrm{BC}}}=\frac{\sum R_{e \kappa \mathrm{C}}\left(1-\mathrm{K}_{o l}\right)+W_{\mathrm{BC}}}{\sum R_{e \mathrm{KC}}+W_{\mathrm{BC}}}
$$

where: $\mathrm{W}_{\mathrm{pM}^{-}}$amount of mined ore mass; $\mathrm{K}_{\mathrm{ol}}$ - ore operational loss factor for the geotechnology used.

If there is associated production of off-balance ores, then this circumstance is taken into account in the above expression by adjusting the volume of operational reserves ( $\left.\sum \mathrm{R}_{\text {eкc }}\right)$ by the amount of mined off-balance ore $\left(\sum \mathrm{R}_{\mathrm{zb}}\right)$.

If, at the next technological level, a part of the rock mass issued becomes an independent resource that can be used either in other technological systems or in the system of integrated subsoil development, then the waste-free coefficient $\left(\kappa_{\mathrm{wf}}\right)$ составит:

$$
\mathrm{K}_{B 5}^{\prime}=\frac{W_{p i}}{W_{\mathrm{pM}}+W_{\mathrm{Bc}}}
$$

where $\mathrm{W}_{\mathrm{pi}}$ - the volume of the breed that has found economic use.

In the process of enrichment, the mined ore mass is divided into concentrate, with which the main amount of the useful component leaves the subsoil development system for other technological systems for further economic use, and into processing waste that remains in the integrated subsoil development system in the form of storage facilities of various types and designs. Waste-free ratio $\left(\mathrm{K}_{\mathrm{bs}}{ }_{\mathrm{s}}\right.$ ) by analogy with all previous technological levels will be:

$$
\mathrm{K}_{B 5}^{\prime \prime}=\frac{W_{\mathrm{pM}} \cdot K_{\mathrm{BK}}}{W_{\mathrm{pM}}+W_{\mathrm{BC}}}
$$

where $K_{\mathrm{B}}$ - the release of the substance into the concentrate. 
In the same way as in the case of rocks, processing waste can be considered a secondary resource that can be used in other technological systems. The zero-waste factor in this case $\left(\mathrm{K}^{\prime \prime \prime}{ }^{\mathrm{B}}\right)$ found from expression:

$$
\mathrm{K}_{B 5}^{\prime \prime \prime}=\frac{W_{\text {от.и }}}{W_{\mathrm{pм}}+W_{\mathrm{Bc}}}
$$

where $\mathrm{W}_{\text {oti }}$ - the amount of primary processing waste that has found application in economic activities.

Overall coefficient for the considered technological level $\left(K_{\mathrm{B} 5}\right)$ calculated as the sum of local coefficients:

$$
\mathrm{K}_{B 5}=\mathrm{K}_{B 5}^{\prime}+\mathrm{K}_{B 5}^{\prime \prime}+\mathrm{K}_{B 5}^{\prime \prime \prime}
$$

According to the above definitions, the integrated development of the subsoil presupposes the maximum utilization of not only the extracted material of the lithosphere, but also the generated waste space as a secondary technogenic resource. This means that it is necessary to include an indicator reflecting the degree of use of the substance, not only extracted to the surface, but also remaining in the depths, in the methodology for quantifying wastelessness in the development of a deposit, considering it as a receptacle of technogenic voids that can be used to solve certain economic problems. Since the total volume of worked out space $\left(\mathrm{W}_{\mathrm{vph}}\right)$ equal to the volume of mined rock mass $\left(\mathrm{W}_{\mathrm{rm}}\right)$, then the coefficient of usefulness of the unexpressed matter of the lithosphere $\left(\mathrm{K}_{\mathrm{B} 6}\right)$ defined as attitude:

$$
\mathrm{K}_{B 6}=\frac{W_{\mathrm{vph}}}{W_{r m}}
$$

When filling a worked-out space with waste rocks or tailings, the volume of this space filled in this way, as well as the volumes of tailings or rocks placed in it, are included in the composition used for economic purposes.

In the case of the application of development systems with the collapse of the enclosing rocks, the entire volume corresponding to the volume of the issued rock mass can also be considered used for economic purposes and are taken into account in this capacity when determining the corresponding local coefficients.

The integral non-waste coefficient for the field development technology as a whole is found as the sum of local coefficients obtained for each technological level:

$$
\mathrm{K}_{B}=\mathrm{K}_{B 1}+\mathrm{K}_{B 2}+\mathrm{K}_{B 3}+\mathrm{K}_{B 4}+\mathrm{K}_{B 5}+\mathrm{K}_{B 6}
$$

The value of the total coefficient can be used to estimate the relative amount of solid waste for the operating mining and processing enterprise, as well as to carry out a comparative analysis of the options considered at the design stage.

\section{Conclusions}

Based on the developed scheme of substance movement in the process of subsoil development, a methodology of waste-free technology is proposed. The basis of the proposed approach is the transition of the lithosphere matter into the final product and waste, which can be assessed as a promising resource for development. To quantify waste-free production, an integral coefficient is used, determined by calculation. 


\section{References}

1. K.N. Trubetskoi, Yu.P. Galchenko Geoecology of the development of the Earth's interior and ecogeotechnology for the development of deposits. (Moscow: Nauchtekhlitisdat, 2015)

2. D.M. Evans, C.E. Zipper, E.T. Hester, S.H. J Water Resour. Assoc., 51, 1436-1452 (2015) $10.1111 / 1752-1688.12322$

3. Y. Feng, J. Wang, Z. Bai, 191, 12-25 (2019) 10.1016/j.earscirev.2019.02.015

4. S.K. Singh, P.K. Srivastava, A.C. Pandey, S.K. Gautam. Water Resour. Manag, 27, 4291-4313 (2013). http://dx.doi.org/10.1007/s11269-013-0408-y.

5. S.K. Singh, P.K. Srivastava, D. Singh, D. Han, S.K. Gautam, A.C. Pandey, India. Environ. Geochem. Health, 37, 157-180 (2015). http://dx.doi.org/10.1007/s10653-0149638.

6. J. Nemčić-Jurec, S.K. Singh, A. Jazbec, S.K. Gautam, I. Kovac, Water Resour. Manag, (2017) http://dx.doi.org/10.1007/s40899-017-0200-x.

7. N. Kumar, S.K. Singh, P.K. Srivastava, B. Narsimlu,. Model Earth Syst Environ, 3(30) (2017). http://dx.doi.org/10.1007/s40808-017-0306-z.

8. N. Kumar, S.K. Singh, V.G. Singh, B. Dzwairo, Model. Earth Syst. Environ, 4, 295310 (2018). http://dx.doi.org/10.1007/s40808-018-0425-1.

9. S.K. Singh, P.K. Srivastava, S. Szilard, G.P. Petropoulos, M. Gupta, Geocarto Int, 115 (2016). http://dx.doi.org/10.1080/10106049.2015.1130084

10. D.L. Skole, W.H. Chomentowski, W.A. Salas, A.D. Nobre, BioScience, 44 (5), 314 322 (1994)

11. L.B. Johnson, C. Richards, G. Host, J.W. Arthur, Freshw. Biol, 37, 209-217 (1997)

12. P.C. Pandey, L.K. Sharma, M.S. Nathawat, Environ. Monit. Assess, 184, 2419-2431 (2012)

13. W.B.R. Martins, R.L. Do Vale, G.C. Ferreira, V.M.S. De Andrade, L.F.S. Dionísio, R.P. Rodrigues, F. De Assis Oliveira, Eastern Amazon Rev. Bras. Ciencias Agrar., 13, 1-9 (2018)

14. Ozaryan Yu.A., Bubnova M.B., Usikov V.I. Gornyi zhurnal, 2, $84-89$ (2020)

15. A.E. Mohamed, Abdel Rahman, M. Mohamed, Metwaly, Adel Shalaby Remote Sensing Applications: Society and Environment, 13, 53-60 (2019) https://doi.org/10.1016/j.rsase.2018.10.004

16. N.J. Coppin, A.D. Bradshaw Mining journal books (London, 1982)

17. M. Glen, Miner. Plann., 38, 29-31 (1994)

18. G. Ricks, Closure considerations in environmental impact statements minerals industry international (London, 1995)

19. K. Prach, P. Pyšek, P. Šmilaue Restor. Ecol., 7, 15-23 (1999)

20. W. Schaaf, Ecol. Eng., 17, 241-252 (2001)

21. P. Sklenička, T. Lhota Landsc. urban plann., 58, 147-156 (2002)

22. P. Andres, E. Appl. soil ecol., 33, 67-78 (2006)

23. V.N. Borisova, Mining and geochemistry of natural systems, 180-185 (M. Nauka, 1992) 24. E.L. Vorobeychik, O.F. Sadykov, M.G. Farafonov, Ecological regulation of technogenic pollution of terrestrial ecosystems (Yekaterinburg: Nauka, 1994) 